\title{
LOS ANALFABETOS Y EL DERECHO A LA BELLEZA: VARIAS HISTORIAS A PROPÓSITO DEL LECTOR
}

Alejandra Araya 


\section{ALEJANDRA ARAYA}

Es directora del Archivo Central Andrés Bello. Licenciada y Magíster en Historia de la Universidad de Chile. Doctora en Historia del Colegio de México. Se desempeña como Académica en el Departamento de Ciencias Históricas de la Universidad de Chile. Es miembro del Consejo del Observatorio del Libro y la Lectura. 


\section{LOS ANALFABETOS Y EL DERECHO A LA BELLEZA: VARIAS HISTORIAS A PROPÓSITO DEL LECTOR}

Sylvia Martínez Rodríguez aprendió a leer alrededor del fuego que su madre, Carolina, hacía todos los días para calentar el hogar y preparar los alimentos, especialmente el pan, que se cocía lentamente en las brasas para ser vendido y para hacer hogar, refugio, rincón caliente en medio de una vida áspera que se endulzaba con las historias que oralmente y en letras de tinta circulaban alrededor. Allí escuchó Sylvia, como en susurros cuando todavía no salía el sol, el cuento del escarabajo y del caballito alado, ¿de dónde sacaría mi mamá esas historias: de su cabeza, de la boca de otros, de los libros?, se preguntaría muchos años después. Gran proeza de Carolina, pues no pudo ir regularmente a la escuela, y entre hijo e hijo salidos de su vientre y muchos otros que se arrimaron a su fuego, casi no hablaba con nadie, no salía si no que para hacer deberes y que ni tiempo para dormir tenía o recostarse en una cama solo para ella interrumpida por las violencias de su marido. Este Juan, sin embargo, frente al mismo fuego, le enseñaba a Sylvia y sus hermanos las letras desde un pliego impreso con enigmáticos dibujos que decía eran dragones, pincoyas, símbolos patrios, punzantes cuchillos descuartizadores de hombres infieles, de amigos traidores, o cuellos flácidos en la horca que hablaban de miserias y tragedias por ella ya conocidas en esas historias de un mundo todavía campesino de sujetos que transitaban hacia la vida de ciudad, como Sylvia que con su madre Carolina de alma gitana se movió de aquí para allá, del sur a la capital, en movimiento pendular. Supo muchos años después, en esas largas conversaciones de la tarde, que esos pliegos se conocían como Liras Populares, no sabía de dónde las sacaba su padre. No sabía tampoco por qué se calificaba de ignorantes a los pobres que sabían leer y escribir y se decía de ellos ANALFABETOS, como un estigma social, porque era imposible que algo pudieran saber, de esa soberbia del de arriba nadie dice que apenas sabían leer, solo un puñado de hombres, y así fueron, en realidad, la primera clase analfabeta funcional a un sistema, su sistema.

Pero volvamos a la historia de los lectores supuestamente imposibles, esos venidos del mundo de la precariedad, pero no de la pobreza cultural. El libro es libre. Volvamos al padre de Sylvia, huérfano criado en un regimiento militar, aprendiendo de su dureza la lectura, la escritura y su oficio de veterinario. El dinero de Juan saciaba dos paraísos, uno artificial, otro de artífice. Con trago, Juan era un demonio, con un libro, una especie de arcángel librero portador de objetos preciosos que con solo abrirse poblaban la mente niña de árboles, animales, personajes, colores, sabores, olores, grandes historias de amor, tragedias, todo un mundo se desplegaba en ese instante, incluso si era desde el grueso vademecum, con sus enigmáticas y sonoras palabras de pócimas curativas. En ese instante, en suspenso el tiempo, entraba a otro tiempo, el de la escucha de historias leídas por otro, narradas por otro o contadas a sí misma en el silencio del pliegue de ese 
territorio que resguarda ese objeto que llamamos libro y que su presencia parece que hemos olvidado: material, carnal, animal, perecible, deseable, relicario de ese universo en que se transforma uno mismo cuando sumamos a nuestra propia historia, la experiencia de ser un lector.

Dicha transformación no es posible, sin que antes exista, la magia del fuego, de la historia contada por otro y que existe antes de que existiese la imprenta, antes de que se encuadernara el primer conjunto de pliegos llamado libro y que hoy —no sé qué lugar pueda tener en eso que llaman "competencia lectora"- literalmente se traduce en que nuestras profesoras y profesores portan un cronómetro para medir la velocidad en que los ojos descifran y la boca articula un sonido. ¿Qué lugar tiene allí el libro y leer? Los niños debieran ocupar ese tiempo en manipular con sus bellas manitas uno de los artificios más fascinantes de nuestra vida moderna. ¿Les habremos hecho escuchar, alguna vez, el tic-tac del tiempo? ¿Cuántos niños de hoy pueden contar entre sus historias la de la bella imagen del péndulo de un reloj?

Para ser un lector, aunque no se sepa leer, se necesita de un espacio para el tiempo, generar los pliegues y repliegues que el cuerpo necesita para iniciar ese viaje que promete toda lectura. Entonces, el libro se despliega y allí empieza otra historia, la del dedo recorriendo continuamente las líneas, o los ojos dando saltos por las ilustraciones que nos llaman a introducirnos en la caja, tomar el hilo de Ariadna y recorrer los laberintos de lo que no se conoce, y gozar, con el goce primario, calórico, para luego ser expulsado, con vértigo, a otras nunca escuchadas, imaginadas, soñadas o pensadas, o tan reales que deseamos, fuertemente, que no lo fueran, que le sucedan siempre a otros, que no nos vuelvan a suceder y el libro sea capaz de contenerla y detener el dolor que alguna vez produjeron en la carne propia.

Detengámonos un momento, démonos un tiempo.

Escuchemos nuestra respiración, volvamos a ese lugar del primer encuentro con un libro, libro de volumen, de texturas, de localización en un lugar específico de una pieza, de un cuarto, de un espacio otro que lo contiene, que lo sostiene y al que decidimos entrar, meter el pie, deslizarnos, caer y no regresar jamás al lugar desde donde partimos. Ese libro que ahora cobra forma dentro de sus cabezas, que parece nuevamente entre sus manos.

Ese libro es otra forma del derecho a la belleza, un derecho que debe tener todo aquel que no sabe que puede ser un lector, un derecho para todos los analfabetos de todas las historias, esos que otros calificaron de tales como sinónimo de ausencia de cultura, pero tal como antes, sin analfabetos, no existe el desafío del libro, de cautivar a un lector, de atraparlo, de salir en su búsqueda, o quedarse atento en un lugar mágico para ser encontrado con luz o sin luz. Hubo un tiempo en que toda la humanidad fue analfabeta, sin alfabetos, hubo tiempos de muchos alfabetos, llegaron otros tiempos de luchas de alfabetos, hubo tiempos en que el alfabeto se hizo otra arma de una conquista, hubo tiempos en que el libro se hizo dueño del alfabeto y se convirtió en un símbolo de lo que algunos llaman civilización y hasta se hizo tirano, para enrostrarle a otros rostros, que no tenían luz de razón, civilización de burgués y cultura en libro; en algunos tiempos algunos libros fueron limitados en su capacidad de abrir mundos y cabezas, en 
otras ocasiones hubo obsesiones por decirnos para qué sirven los libros y hoy estamos tentados de canonizar solo algunos tipos de lecturas, señalando con el dedo a quienes, tan lectores como cualquier otro, se deleitan con novelas policiales hasta morir con una de ellas en el bolsillo (como uno de los hermanos de Sylvia), o hacer decir con culpa que el primer libro que los apasionó, que los animó a leer de la primera y última página de un tirón, fue uno de aventuras del oeste norteamericano, un best-seller, la revista Life, las Confidencias, Margaritas, Zig-Zag, las historias de Corín Tellado... en fin. Si decimos que hoy que existe una crisis del libro y la lectura, será, digo yo, por crisis de la imaginación, de falta de pasión, por falta de creatividad y de curiosidad, por falta de coraje. Si quiere eliminar el IVA, ipues elimínelo, señor!

Un libro nos empuja hacia nosotros mismos y hacia otros, desconocidos, de miles de tiempos. Las historias nunca lo son sin otro, aunque estemos solos disfrutando de la soledad.

No pensemos en el autor, pensemos en todos los artífices del libro, en la pericia de todos aquellos que de diversos modos inventaron ese objeto para atrapar a un lector, una trampa que llama a un cuerpo a acercarse a ese otro cuerpo. Una especie de caja (la cubierta), una especie de puerta (la portada), un objeto de deseo.

Tomo de una historia oída a una hermosa amiga, de nombre Ariadna, de carne y hueso, encontrada en los inventarios de bienes de hombres y mujeres del siglo XVII en esta Capitanía General de Chile o en el Reino de Chile para adornar mejor el cuento, de grandes y pequeñas fortunas, de ningunas fortunas y hasta en ausencia de escritura. Ella me dijo, en susurro, con cierto nerviosismo, pues parecía que no debieran estar allí (libros en tierras bárbaras, libros entre gente que no sabe escribir, libros entre mujeres, libros entre negros, entre indios, novelas de diversión en serias colecciones de obispos...). Ese libro se despliega ante sus ojos, y por medio de ella a los míos, y de mi boca a los cuerpos de ustedes en este momento, como los más hermosos objetos que jamás hayamos imaginado que estuviesen allí y descritos con las más hermosas palabras que en el último tiempo oí: encuadernados con candados de plata, con hojas de marfil o tapas de badana, con tapas de pergamino, con cubierta de papel pintado y sin pintar, en papel de marca, forrados en terciopelo, en pasta blanca, pasta negra y dorada, tablillados, tomos de oro, desiguales, con manecillas, con tapas de tafilete grabado, a la rústica, a telas, con pasta económica, con tapas rotas y viejas, sueltos. Y se suman a ellos en el siglo XIX las tapas de tisú de seda, el terciopelo carmesí, el tafilete azul, las láminas de hierro, forrados con papeles rayados, con láminas grabadas, pastas coloradas, verdes, amarillas, lacres, moradas...

Libros con manecillas para tocarnos y otros sueltos para poder huir del lector...

Esas hermosas cajas misteriosas que deben ser los libros en nada se parecen a las cajas de artículos de toda clase producidos por nuestra era del consumo industrial que muchos señalan como el colmo del llamado "analfabetismo funcional"... ¿qué es eso? Nos dicen: que alguien, sabiendo leer, no comprende lo que lee. Sí, es altamente posible, no sé con qué estadísticas o datos de otros tiempos se comparan estas de hoy para decir que los que hoy saben leer comprenden menos que los que sabían leer antes. Supongo que se quiere decir que, habiendo aumentado el nivel de escolarización, por lo 
tanto, el número de los que saben leer y escribir al mismo tiempo, hay personas que no comprenden lo que leen. No entiendo la relación ni la conclusión. Es obvio, hay cosas que se comprenden y otras que no, la competencia lectora no es igual a ser un lector. Con velocidad, yo no puedo comprender nada. Sin espacio para la conversación y el comentario de lo que se lee, por muy letrada que sea, no quiero comprender nada. Ser lector es ser primero un escucha en nuestro interior. La escuela, hasta donde sé, jamás propició dicho conocimiento, siempre fue el encuentro con una gran maestra o profesor, con un amigo incitador de la curiosidad, un encuentro inesperado en la biblioteca de una mesera del litoral lo que lo propició.

Analfabetos funcionales... me huele a paternalismo y pedantería, pues aunque no se diga, se está diciendo que hay una masa de ignorantes letrados que no compran libros. Dejemos la pedantería de cierta cultura del libro que mira con desdén a todo aquel que no lee a los "grandes" y que, en afán de dar lección y señalar políticas para fomentar la lectura, le falta el respecto a tantos y tantas diciendo que queremos que lean para que al menos comprendan las instrucciones de una caja de cartón... jinstrucciones! Es decir, queremos alfabetizados funcionales. Yo no quiero eso señor, quiero que ese hombre o mujer brinque sobre la caja de cartón, se meta en ella, vuelva a salir, la desarme, la recicle y con ella, en forma de hojas, pueda tomar un respiro, sentarse, recostarse o dormitar sobre un bello libro.

Lo que debemos procurar es que exista un mundo posible para el lector, ese mundo ya se los he contado, necesita de una forma de vivir el tiempo como espacio de reposo, de repliegue, de gozo: de la cama, de un sillón, de un asiento, de un paisaje, de una pieza, de una plaza, de una banca, de un rincón para sí, ya ni siquiera de un cuarto para sí, pues en realidad la precariedad hoy se juega en una precariedad total de nuestra condición humana. Entonces el libro, como descubrieron los analfabetos, era un lugar. Ellos anidan, me dijo hermosamente un amigo que los restaura y que sabe cuidarlos para que sigan permaneciendo. Y anidan en cualquier parte, pero necesitan de un recoveco para quedarse, un calor animal: un bolsillo, el pecho, el velador.

Que exista espacio para el libro es una exigencia para que pueda existir un lector. Nuestro deber es hacer libros como producción de belleza, todos estamos obligados a ello, no obligar a leer, ellos deben estar y existir para ser encontrados por quienes tengan, como parte de su ser, la curiosidad, y no tengan temor de ser sorprendidos, conmovidos, removidos. La belleza se percibe, es cierto, pero es por sobre todo una emoción que se activa cuando otro aparece frente a nosotros y nos llama desde allí, desde arriba del armario donde la madre ocultaba las novelas que solo podían leer los adultos, desde la gran biblioteca que no era nuestra y que siempre nos decía "llévame, tómame, bébeme"; desde las noches en que la madre llevando de la mano a su hija reencontrada le contaba la historia de la luna; desde la enciclopedia ilustrada con voraces plantas carnívoras saliendo de sus bordes dorados, o de esas tapas duras olorosas, sabrosas como crujientes galletas de la tarde.

Ese derecho a la belleza necesita ser proclamado como todo derecho a ser humano y no un ser funcional. Probablemente, la primera gran cualidad que debe tener un lector es ser disfuncional, preferir la calma por sobre la velocidad, preferir el comentario 
verbal al WhatsApp, preferir el rostro furioso o emocionado de su amigo frente a frente y aprender de las emociones fuera del computador. El computador, como el libro, no debe ser tirano de un mundo, estará allí, pero en un nicho en el que existen otros mundos, mundos del cuerpo, del oído a la vista, de la vista al oído, del sabor al olor, de los desplazamientos ficticios, reales, virtuales, de las promesas. Desplazarse, recorrer, vivir.

¿Podía saber la maestra rural que su lectura pausada y llena de inflexiones en su voz, al leer El Mago de Oz a la pequeña Sylvia, la harían llorar de emoción cuando ella vio la película porque era exactamente igual a como la había imaginado? En medio de la dureza, de tantas batallas, de tanta tristeza, en un mundo precario, lo único que nos salva es el derecho a la belleza. Los libros no llegaban a esas casas de Sylvia, los encontraba por allí en sus búsquedas; los libros no llegaban a las casas de su hija Alicia, los conseguía por allí, la encontraron a ella en sus escuelas, la dejaron en medio de los ajetreos de la vida casadera, pero la buscan siempre, la encuentran. Del corto presupuesto de que disponía para la vida cotidiana de su precaria casa, decidió un día hacer algo peligroso por la vida de sus hijas. Compró en cuotas, en secreto, el Pequeño Larousse de tapa roja, la Biología de Villee y La Tierra y sus recursos. En ellos, las pequeñas tareas de la escuela podían resolverse, pero no pudo imaginar lo que ese temerario gesto provocó en una de ellas, pues escondidos en un escritorio de metal solo podían ser usados cuando el padre no estaba, pues esos extraños objetos de ninguna necesidad provocarían la airada pregunta de con qué los compraste y quizás cuántos otros desastres más. Las niñas obedecieron y guardaron el secreto, ese hermoso secreto que alimentó muchos sueños, que aumentó la sonoridad de las palabras, que ilustró un planeta desconocido y hasta les mostró que se podían escribir miles de cosas y contar miles de cosas si formaban parte de un mundo de otros juegos, risas y torpezas. Ese hombre no entendía las letras ni los libros, porque nadie cultivó su derecho a su belleza. Pasando el tiempo, dejó entrar los libros, mirando de reojo, con el ceño fruncido. Así Alicia fue haciendo una pequeña biblioteca para sus hijas, y el hombre hizo con sus manos un mueble llamado biblioteca. Allí estuvieron por muchos años los tres primeros libros, se sumaron los libros por entregas del quiosco de la esquina, los libros usados de San Diego, así llego el libro-biblia de otra pequeña Alicia, de las maravillas, reliquia que llevará hasta el fin de sus días.

Al final de los días, un libro acompañará a los analfabetos, el gran libro de la palabra de todos los dioses reunidos, o el gran libro de las palabras de sus seres queridos reunidos. Allí, en torno al último suspiro, en medio de las cenizas del fuego que se vivió, estará la primera historia de todos los libros. 